\title{
The Two-Communities Theory and Knowledge Utilization
}

\author{
NATHAN CAPLAN \\ University of Michigan
}

Even though the amount of empirical data on social science utilization in policy formulation is limited, the literature abounds with social scientists speculation about why the information they produce has little impact on policy matters. Either explicitly or implicitly, the most prevalent theory found in this literature may be characterized as the "Two-Communities" theory.

Authors who hold this view attempt to explain nonutilization in terms of the relationship of the researcher and the research system to the policy maker and the policy-making system. They argue that social scientists and policy makers live in separate worlds with different and often conflicting values, different reward systems, and different languages. The social scientist is concerned with "pure" science and esoteric issues. By contrast, government policy makers are action-oriented, practical persons concerned with obvious and immediate issues. Some argue that the gap between the knowledge producer and the policy maker needs to be bridged through personal relationships involving trust, confidence, and empathy. Others see this gap as something apart from cultural differences. They stress conflict over who determines the ends of policy as an important factor that keeps the social scientists and policy makers apart.

Some feel that the spectre of knowledge misuse by political power tends to widen the gap. Still others, particularly those who argue the need for "linking" mechanisms, see the gap as a com- 
munication failure or a lack of organized effort to systematically introduce social science knowledge in usable form into the policymaking process at the key points where it will most likely be used. The general argument is similar in many ways to C. P. Snow's position in The Two Cultures, in which he examines the gap between those in humanities and those in the hard sciences. ${ }^{1}$ It is my purpose to examine the relevance of the practices associated with the Two-Communities position and to the problem of increasing the utility of social science knowledge in policy-related issues among federal executives.

\section{IS THERE REALLY A GAP?}

The answer to this question is most certainly "Yes." Recently, I directed a study (Caplan, Morrison, and Stambaugh, 1975) in which 204 upper-level executives in policy-influencing positions in the U.S. government were interviewed regarding their use of social science knowledge in policy-related issues. These respondents were carefully questioned to determine if they were in contact with an influential network of scholars, or "invisible college," with expertise in social science fields relevant to the respondents' area of policy responsibility. Responses to these items showed that no such liaison exists and that contact, formal or informal, between social scientists and upper-level decision makers is rare. Poppen (1978) obtained responses to the same set of questionnaire items for social scientists involved in policy relevant research and also concluded that a gap, or what Weiss (1976) calls the great divide, exists between knowledge producers and users.

\section{THE SIGNIFICANCE OF THE "GAP"}

Although upper-level policy makers are isolated from prominent social scientists and are largely unaware of their work, the importance of the Two-Communities gap with regard to utilization is not immediately evident. It is, however, tempting to con- 
clude that the lack of direct contact with knowledge producers may have special significance for utilization. A multivariate analysis of attitudinal data from these respondents showed that when sets of variables associated with Knowledge-Specific, Policy Maker-Constraint, and the Two-Communities theories of underutilization were compared, the items representing the TwoCommunities position accounted for the largest proportion of explained variance between users and nonusers. Further, there was considerable evidence that government executives do not need to be conviced of the potential usefulness of scientific information. A high degree of interest in the receptivity to social science information for the purposes of policy formulation was indicated by the high response rate and by responses to a number of selected interview items bearing on the potential contribution of social science research to the improvement of government policies.

If the attitudes of these respondents accurately represent their experiences and their efforts to understand utilization, then these findings would strongly suggest that social scientists would be well advised to pay particularly close attention to the utilization theories that stress the lack of interaction between social scientists and policy makers as a major reason for uonuse.

It does not follow from our data, however, that an alliance of social scientists and policy makers is the panacea which will produce relevant research and allow translation of the results of scholarly analysis into terms of practical politics. The notion that more and better contact may result in improved understanding and greater utilization may be true, but there are also conditions where familiarity might well breed contempt rather than admiration. The need for reciprocal relations between knowledge producers and knowledge users in policy-making positions is clear, but the problem of achieving effective interaction of this sort necessarily involves value and ideological dimensions as well as technical ones.

Further, it is unlikely that any single system for linking producers and users could be applied broadly. Linking arrangements may depend upon the nature of the problem. A better under- 
standing of utilization-underutilization, nonutilization, premature utilization and overutilization-would seem necessary to to successful knowledge transfer. Differences in the significance of the policy decision under consideration will be used here to illustrate the importance of giving attention to the variety of factors associated with utilization before attempting to link the producer and user communities.

\section{MICRO-LEVEL PROBLEMS: INSTRUMENTAL UTILIZATION}

In the study of upper-level executives, approximately $90 \%$ of reported instances of use were associated with day-to-day policy issues of limited significance, usually involving either small segments of the population or the user's own organization. At least one-third and possible as many as one-half of these applications involved administrative policy issues pertaining to bureaucratic management and efficiency rather than substantive public policy issues (Caplan, 1976a). Most often the primary purpose of such knowledge application was to test the acceptability of already established programs and policies, or to measure progress or retrogression with respect to the success of such efforts. Because of the narrow scope represented by these decisions, they can be thought of as "micro-level" decisions. Three-quarters of the data used in micro-level decisions was produced in-house or commissioned under contract by the using agency. Finally, the data used were ordered by the decision maker for a specific purpose. Thus, knowledge application at this level involves the use of data ordered by the end user, produced by the user's agency and most often applied with a veiw to improving management of the agency's internal operations (Caplan et al., 1975, 1976a).

This type of use represents the straightforward reaction of the agency's utilization system to some obvious realities. Most of the policy-related information needs in any governmental agency are of this sort, and it is valuable to know that such decisions are often premised on empirically based knowledge. Moreover, such 
instrumental applications need not mean that the issues involved are necessarily trivial. The major problem is that preoccupation with knowledge application of this type leads to a technological conception of knowledge use which dominates thinking about utilization and how it may be improved. Caplan (1974), Rich (1975), Weiss (1976), and Knorr (1976) have all recognized the prevalence of "instrumental" utilization. ${ }^{2}$

Most information transfer procedures based on the TwoCommunities theory would be suitable for policy decisions involving instrumental application. However, the major problem is not how to increase the amount of instrumental application. Either by producing its own data or by contracting for information, the government appears to have available the information deemed requisite for dealing with micro-, intermediate-, and administrative-level issues. Linkages between researchers and those in the middle-level bureaucratic positions of the agency have been established, and such linkages are apparently functioning adequately in knowledge applications involving micro-level decisions.

The greater problem arises from the fact that scientific knowledge use in public policy is not fully realized because of this emphasis only on the most practical aspects of its value. Further, emphasis on this instrumental type of application leads to a conception of utilization possiblities which is entirely different from that necessary to deal with meta-level issues: information gathered and applied in this way results in an image of reality too narrow to provide a suitable foundation on which to premise decisions involving the more important policy issues.

\section{META-LEVEL PROBLEMS: CONCEPTUAL UTILIZATION}

Although the federal executives studied participate in deliberations involving the use of scientific information in micro- and intermediate-level policy issues, they also deal with macro-level 
decisions. Approximately $10 \%$ of the instances of knowledge applications reported by respondents involve important policy matters which affect the nation as a whole. At this level, only rarely is policy formulation guided by concrete, point-by-point reliance on empirically grounded information alone. This is not to deny that many respondents cited the use of specific social science research studies in discussing important decisions, but such information was usually only one of many sources used. Rather than relying upon any single piece of information, the final policy decision was likely to depend upon an appraisal of scientific (hard) and extra-scientific (soft) knowledge from a variety of sources. Both types of knowledge are combined conceptually, resulting in a judgment or a perspective which is then applied broadly to decisions involving problems at the meta-level range. ${ }^{3}$ Conceptual utilization as described here generally goes unrecognized or at best is referred to obliquely in empirical research on utilization.

The importance of conceptual utilization is evident from responses to the following item: "On the basis of your experiences in the federal government, can you think of instances where a new program, a major program alternative, a new social or administrative policy, a legislative proposal or a technical innovation could be traced to the social sciences?" It should be noted that this item did not specify that the respondent limit his or her answer only to applications involving empirically gounded research findings. The $82 \%$ of the respondents who replied "yes" to this question were asked to be specific and to provide examples.

Among the approximately 350 examples given, the policy areas represented ranged widely. They were as likely to be of a technological or medical nature as they were to be strict social policy issues. To illustrate, the following decisions were offered as examples: to establish water and sewer construction assistance programs and highway construction projects such as the interstate system; to transfer to an all-volunteer army; and to select particular diseases, such as sickle cell anemia and cancer, for major governmental research funding; to establish the 
leadbased paint prevention program, the Headstart Program, the Environmental Protection Agency, manpower and development programs, the GI Bill, consumer information programs, revenue sharing, and major programs to "humanize" service delivery programs. All of these and many more programs involving governmental actions of considerable national importance were in some way credited by our respondents to information from the social sciences, yet rarely were they able to cite specific know ledge sources.

Such decisions appear to be the result of combining two basic approaches to problem solving. First, policy makers gather and process the best available information they can obtain to make an unbiased diagnosis of the policy issue. They use knowled ge in this way to deal with what may be called the "internal logic" of the the problem. Next, they gather information regarding the political and social ramifications of the policy issue, to deal with what may be termed the "external logic" of the problem. To reach a policy decision, they finally weigh and reconcile the conflicting dictates of the information. Thus, more so than in the case of instrumental utilization, the inquiry process involved in conceptual utilization depends upon the properties of the individual rather than upon those of the bureaucracy.

Whereas the policy makers studied generally rely almost exclusively upon routine agency sources of information for reaching decisions regarding micro-level issues, they were eclectic in their use of information for decisions involving issues of greater consequences. In addition to government reports and staffsupplied information typically relied upon so heavily for microlevel decisions, the meta-level decisions were influenced by information acquired independently by polic makers from diverse sources external to government-sources such as newspapers, books, professional journals, magazines, television, and radio. At least $50 \%$ of the respondents studied mentioned each of these as important sources of "social science" information. Rarely, however, were such sources cited when respondents were questioned on the use of "empirically grounded" information. Thus, when dealing with policy matters 
of lesser importance, the respondents appear to have relied almost exclusively on agency sources for information; when dealing with macro-level policy issues, they acted more independently in gathering, organizing, and analyzing knowledge perceived as relevant.

Regardless of the scientific merit of this knowledge-based perspective, which plays such an important role in conceptual utilization, the fact is that these respondents exhibited great sensitivity to informal sources of information bearing on social issues and contemporary social reality. Further, while this perspective may include the use of agency-supplied, empirically based knowledge, the strong impression is that more general forms of social science knowled ge (soft knowledge) are important far more often in upper-level policy decisions than specialized scientifically premised (hard) knowledge typically provided through routine channels of information.

\section{COLLABORATION FOR CONCEPTAL UTILIZATION}

There are special considerations which argue for the importance of bridging the social science and policy-making communities with respect to knowledge use at the macro-level. First, while an agency may provide technological information sufficient for micro-level application, it cannot meet the information requirements for macro-level policy deliberations. Second, budgetary and bureaucratic constraints prevent each agency from devoting a large proportion of its resources to the gathering of data whose purposes cannot be specified in advance and whose quality cannot be measured against traditional criteria of scientific proof. Third, the problems associated with the storage of multiple-purpose, largely conceptual data would be enormous.

A fourth problem encounted is that even though these upperlevel officials are eclectic in their search for information pertaining to meta-level decisions, they do not come into touch with 
the most pertinent or cogent knowledge available. In fact, "parochialism" is the most apt description of their application of knowledge, even with respect to macro-level issues (Caplan, 1976b). And, fifth, the kind of information that enters into metalevel decisions often can only be gained from the expertise and judgments of persons experienced in matters pertinent to the issues under consideration. Such individuals are as likely to be found outside of government as within it.

A sixth and final reason for collaboration is that it may be the only means to reduce the degree to which chance and purely adventitious events determine the nature of information used in meta-level decision making. Policy formulation may depend upon whether a policy maker happens to read a particular position paper, and whether he or she comes across a finding reported in the media - events which are often the result of seemingly capricious sets of circumstances.

What is needed is a set of arrangements deliberately designed to supplement agency-provided information with other kinds of knowledge vital to national policy decisions. It is in this context that bridging the gap between research scholars and policy makers would be beneficial. This is not to say that such persons could be expected to provide the policy makers with a kind of "knowing" that will give answers to questions such as what values are "right" or the directions policy should take in order to provide the "good life" for its citizenry. But the experienced research scholar would be in a good position to formulate judgments on the appropriateness of various types of social science information in relation to policy makers' interests and needs. The role played by the scientist would vary substantially depending on the information and policy issues involved. But at a minimum, he or she would be capable of making realistic appraisals of the relative merit of diversified social science information, linking persons with relevant expertise (some of whom may not be researchers) to the policy setting; recognizing and distinguishing between scientific and extra-scientific knowledge needs; and redefining issues in terms that may make them more amenable to solution or which allow them to be viewed from a different perspective. The 
importance of individual experience or internship in the policymaking process also bears emphasis. Charles Frankel's (1969) account of his stay in the State Department and his notion of the "in-and-outer" (academics who go in and out of government service) seems particularly pertinent in this regard.

\section{CONCLUSIONS}

My purpose has been to show that the connection between knowledge producers and users has to be thought out carefully if efforts to improve utilization based on the Two-Communities theory are to succeed. To couple existing knowledge and the production of new knowledge to user needs requires collaborative arrangements which will be congruent with the nature of the utilization problem and the existing system of inquiry used to acquire and process information. The problems encountered in metalevel and micro-level decision making illustrate the relevance of the Two-Communities perspective to the needs of upper-level government officials in dealing with public policy issues which affect the nation. While the potential for improving utilization at this level of social problem solving is great, such arrangements will be unlikely to succeed if premised on the technological conception of knowledge use which now dominates utilization theory, research, and action. The theory has led to "linkage" which has increased the quantity but not the quality of utilization. Such arrangements may be appropriate for the use of applicationoriented empirical findings to micro-and administrative-level problems, but they are likely to be inappropriate in dealing with meta level problems. Collaboration at this level must be concentrated upon dealing with issues which involve more general problems, the formulation of the problem, assisting the policy maker in knowing what he or she has to know, and, finally, an understanding of which aspects of the problem are to be decided on the basis of data-based knowledge and which ones are to be decided on the basis of non-research knowledge. 


\section{NOTES}

1. The emphasis on linkage techniques based on utilization practices derived from research on communication and the spread of innovations (Katz and Lazarsfeld, 1955; Rogers, 1962; Rogers and Schumacher, 1971). Lippitt (1965) developed a similar approach based on sociopsychological findings. Conceptualization and theoretical discussions of the two-communities position can be found in Havelock (1971), Harary and Havelock (1972), and Glaser and Taylor (1972). Recent collections of articles on utilization such as those edited by Weiss (1977) and Scribner and Chalk (1977) attest to the widespread popularity of the approach.

2. It is also worth noting that knowledge used in micro-level decisions is amenable to empirical study and, in consequence, the kind of knowledge use about which we know most. It can be studied because the purpose for which it is gathered can be usually specified in advance and it is usually possible to trace the utilization process as a set of sequentially linear and predictable input-output processing steps. Further, because of the character of such application, it is possible to measure whether or not intended use occurred. Unfortunately, however, because instrumental application lends itself to empirical study, it receives attention at the expense of other uses of knowledge (e.g., conceptual utilization) whose effects are less predictable, but whose impact on policy may be considerably greater.

3. The generalizability of the knowledge-based perspective is important to keep in mind. Not only does information used in this way have more "power" in the sense that its application involves issues of national priority, but it also has an added dimension over instrumental-type applications in that it can be applied to a variety of issues beyond the routine boundaries of what is considered social policy. It is applied in policy matters that have social consequences, a fact which virtually involves it in all major public policy consideration.

\section{REFERENCES}

CAPLAN, N. (1976a) "The use of social statistics by federal executives with special attention to policy decisions in education," pp. 75-88 in Setting Statistical Priorities. Washington, DC: National Research Council.

(1976b) "Social research and national policy: who uses what, for what purposes and with what effects," International J. of Social Sci. 28 (1): 87-194.

___ (1974) "The use of social science information by federal exeuctives." Presented at the OECD Conference on Social Research and Public Policies, Dartmouth College, Hanover, New Hampshire. Published in G. M. LYONS [ed.] (1975) Social Research and Public Policies. Hanover, NH: Dartmouth Press.

-_- A. MORRISON, and R. STAMBAUGH (1975) The Use of Social Science Knowledge in Policy Decisions at the National Level. Ann Arbor: University of Michigan Institute for Social Research.

FRANKEL, C. (1969) "Being in and being out." Public Interest 17: 32-43. 
GLASER, E. and S. H. TAYLOR (1971) "Factors influencing the success of applied research." Amer. Psychologist (February): 140-146.

HARARY, F. and R. HAVELOCK (1972) "Anatomy of a communication arc." Human Relations 25, 5: 413-426.

HAVELOCK, R. (1971) "The utilization of educational research and development." British J. of Technology 2, 2: 84-96.

KATZ, E. and T. S. LAZARSFEl.D (1955) Personal Influence: The Part Played by People in Mass Communications. New York: Free Press.

KNORR, K. D. (1976) "Policy-makers' usc of social science knowledge: symbolic or instrumental?" in Proceedings of the First International Conference, Society for Social Studies of Science. Ithaca, NY: Corncll University.

L.IPPITT, R. (1964) "The use of social research in improving social practice." Amer. J. of Orthopsychiatry 35 (July): 663-669.

POPPEN, P. (1968) "Social scientists' attempts to influence public policy." SPSSI Newsletter 148: 10-12.

RICH, R. F. (1975) An Investigation of Information Gathering and Handling in Seven Federal Bureaucracies: A Case Study of the Continuous National Survey. Ph.D. dissertation, University of Chicago.

ROGERS, E. (1962) Diffusion of Innovations. New York: Free Press.

and F. SCHUMACHER (1971) Communications and innovations: A CrossCultural Approach. New York: Frec Press.

SCRIBNER, R. and R. CHAL.K [eds.] (1977) Adopting Science to Social Needs. Washington, I)C: AAAS.

WEISS, C. [ed.] (1977) Using Social Research in Public Policy-Making. Lexington, MA: lexington Boohs.

_- (1976) "Research for policy's sake." Presented at a Symposium on Applied Sociology: Patterns and Problems. Case Western Resence University, Cleveland, Ohio. 